\title{
Lung Adenocarcinoma by AJCC v7 Stage
}

National Cancer Institute

\section{Source}

National Cancer Institute. Lung Adenocarcinoma by A/CC v7 Stage. NCI Thesaurus. Code C136490.

A term that refers to the staging of lung adenocarcinoma, following the rules of the TNM AJCC v7 classification system. 